\title{
Linguistically Appropriate Practice: A Guide for Working with Young Immigrant Children
}

\author{
Written By: Roma Chumak-Horbatsch \\ Reviewed by: Maria Claudia Petrescu
}

\begin{abstract}
Maria Petrescu is a $\mathrm{PhD}$ candidate at Ontario Institute for Studies in Education at the University of Toronto in the Language and Literacies Education program. Her research interests include child language acquisition, bilingualism/multilingualism, minority language learning and maintenance, and heritage languages. Her $\mathrm{PhD}$ research focuses on documenting the bilingual development and bicultural experiences of Romanian-speaking Canadian children.
\end{abstract}

It was with great curiosity that I started to read Roma Chumak-Horbatsch's Linguistically Appropriate Practice: A Guide for Working with Young Immigrant Children, since it covers an area dear to me as a graduate student, that of bilingual children's education. My curiosity came not only from the researcher in me, but also from my role as parent of two young bilingual children. I was curious to find out how and what classroom practices could support the maintenance and development of bilingual children's heritage languages, as my wish for my children is to continue to be bilingual even when they attend school in English. So, my double role as parent and graduate student drew my attention to this book immediately.

The purpose of the book is multifold, and it reflects the diversity of its intended audience. The book offers practical solutions to the challenges encountered by educators in childcare centres and primary schools where immigrant children do not speak the classroom language. It also provides answers to parents who value and encourage heritage language maintenance and who might wonder what is best for their children in terms of bilingualism. Last but not least for all the workers, educators, and policy makers involved in early childhood education in Canada, it describes in detail a plan for an inclusive learning environment in which all children's linguistic, cultural, personal, and intellectual richness is supported and validated.

The book is organized into three main parts. "Laying the Groundwork for Linguistically Appropriate Practice (LAP)" provides background information about immigrant children. Part 1 contains four chapters; in the first three, the author answers questions related to (1) the presence and the linguistic situation of immigrant children globally and in Canada, (2) current classroom practices with young immigrant children, and (3) why we need a new approach in how we help immigrant children. A detailed description and explanation of the new approach, LAP, is provided in Chapter 4.

Part 2, "Setting the Stage for LAP," offers a detailed description of how ECE practitioners can prepare their classes for LAP and what has to be in place before launching LAP in their classrooms.

Part 3, "Implementing LAP Activities," offers a series of practical classroom activities that can be used as they are or adapted to children's diverse needs.

By identifying a gap in the current classroom practices with regard to the language and literacy needs of young immigrant children, by providing a rationale for the need for a new approach, by rigorously planning and organizing the book, and by clearly presenting practical suggestions and examples, ChumakHorbatsch has succeeded in producing a much-needed resource that offers a comprehensive overview of the linguistic and cultural situation of Canada's immigrant children. She proposes inclusive language and literacy practices that will enrich the academic experiences of all children. Although these are definite signs of success for the book, a few things make me consider the book particularly valuable and outstanding.

First, while reading the book, I could not help but appreciate the author's clear definition of the construct linguistically appropriate practice (LAP). In the introduction, the author relates the birth of LAP while jogging in Toronto's High Park, telling an audience of sleepy Canada geese that LAP would be "inclusive, research based and practitioner friendly" (p. 4). Chapter 4 is dedicated in its entirety to defining the new approach, describing LAP's theoretical grounding and the absolute, immediate necessity of a new way to work with immigrant children. The author explains how the proposed classroom practice extends inclusive practices and reflects the principles of dynamic bilingualism in a way that takes into account all language circumstances, contexts, and speakers. Thus, ChumakHorbatsch writes, "LAP sees immigrant children as emergent bilinguals, acknowledges their unique language and literacy needs, focuses on the social and communicative aspects of languages, encourages translanguaging, promotes bilingualism, and builds partnerships with families" (p. 57).

Another important aspect of the book's success is the presence of concrete examples in the form of activities and lesson plans on how LAP can be put into practice in the classroom. As willing as practitioners often are to provide the 
best instruction for all children, they are just as often at a loss when it comes to putting into practice new theories that promote child growth because of the lack of clear guidance, proper support, and training. Chumak-Horbatsch's inclusion of this guidance and support gives the book extreme value and sets up the new approach for success. Not only does she promote a new classroom practice of inestimable value to developing and maintaining heritage languages by immigrant children, but she also provides very carefully planned and detailed activities and lesson plans that will help practitioners set the stage for and adopt LAP in their classrooms. After she describes each activity in detail, the author offers tips and suggestions with regard to expanding and extending the activities to make them suitable and appropriate for the children's needs. The fact that the activities have been through a "tried and tested" process by being rigorously developed and implemented throughout the years by the author herself or by other practitioners and researchers speaks to the efficiency and success these activities bring to a class.

In my opinion, LAP's overall value stems from its significance for pedagogy. The call for supportive approaches to children's home languages and cultures in preschool and elementary classrooms is nothing new, but unfortunately, that is what it remained for a long timejust a call waiting to be answered in a proactive way that comprehensively addresses the language and cultural needs of bilingual children. The brilliance of Chumak-Horbatsch's book stems from the fact that it goes a step further-a huge and important step, I might say-and provides educators with what the field was lacking - concrete examples of how inclusiveness can be achieved. In other words, the book successfully makes the link between theory and practice.

Although I am not currently an early childhood educator, I absolutely enjoyed the group activities section included at the end of each chapter. The section took me on a journey back into the past and helped me to reflect on my past beliefs and practices with the bilingual children I once taught and to remember those years with warm feelings. I took tremendous joy in carrying out some of the activities on my own and appreciated the new tips I learned that will help me with my current home practices with my children.

Last but not least, the book is extremely reader friendly. The book's attractive format is clearly explained in the introduction and is followed throughout. I particularly liked the easiness of the read and the lack of pretentious terms. A list of definitions for terms used throughout the book is provided in the introduction, with additional explanations inserted throughout the book, making the book accessible for everyone. The inclusion of anecdotes, photos, and stories makes the argument for a new approach more convincing and real. Whether you are a policy maker, an ECE instructor, or a parent, this book draws you into wanting to become part of an inclusive communitythe LAP community.

To conclude, Linguistically Appropriate Practice: A Guide for Working with Young Immigrant Children has something to offer everyone involved in the education of bilingual children. The book provides researchers and graduate students like me with a comprehensive overview of the linguistic situation of Canada's immigrant children. It proposes a new, inclusive, and supportive language approach to the classroom practices in daycare centres with immigrant children and offers practical suggestions and ready-to-use activities and lesson plans. For language policy makers and curriculum planners, the book makes a call for carefully building a curriculum that is inclusive of the language learning acquired at home and that enables immigrant children's continuous development.

\section{References}

Chumak Horbatsch, R. (2013). Linguistically appropriate practice: A guide for working with young immigrant children. Toronto, ON: University of Toronto Press. 